\title{
Effects of Nuclear Power Plant Thermal Effluent on Marine Sessile Invertebrate Communities in Southern Taiwan
}

\author{
Yalan Chou \\ Institute of Marine Biology, and NCKU-NSYSU Research Center for Ocean Environment and Technology, National Sun \\ Yat-sen University, 70 Lien-hai Road, Kaohsiung, Taiwan 804, R.O.C. \\ Ta-Yu Lin \\ Institute of Marine Biology, and NCKU-NSYSU Research Center for Ocean Environment and Technology, National Sun \\ Yat-sen University, 70 Lien-hai Road, Kaohsiung, Taiwan 804, R.O.C. \\ Chen-Tung Arthur Chen \\ Institute of Marine Geology and Chemistry, National Sun Yat-sen University, 70 Lien-hai Road, Kaohsiung, Taiwan 804, \\ R.O.C.

\section{Li-Lian Liu} \\ Institute of Marine Biology, and NCKU-NSYSU Research Center for Ocean Environment and Technology, National Sun \\ Yat-sen University, 70 Lien-hai Road, Kaohsiung, Taiwan 804, R.O.C., lilian@mail.nsysu.edu.tw
}

Follow this and additional works at: https://jmstt.ntou.edu.tw/journal

Part of the Terrestrial and Aquatic Ecology Commons

\section{Recommended Citation}

Chou, Yalan; Lin, Ta-Yu; Chen, Chen-Tung Arthur; and Liu, Li-Lian (2004) "Effects of Nuclear Power Plant Thermal Effluent on Marine Sessile Invertebrate Communities in Southern Taiwan," Journal of Marine Science and Technology. Vol. 12: Iss. 5, Article 12.

DOI: $10.51400 / 2709-6998.2267$

Available at: https://jmstt.ntou.edu.tw/journal/vol12/iss5/12

This Research Article is brought to you for free and open access by Journal of Marine Science and Technology. It has been accepted for inclusion in Journal of Marine Science and Technology by an authorized editor of Journal of Marine Science and Technology. 


\section{Effects of Nuclear Power Plant Thermal Effluent on Marine Sessile Invertebrate Communities in Southern Taiwan}

\section{Acknowledgements}

We are most grateful for financial support from the Taiwan Power Company and the joint project of National Cheng-Kung University and National Sun Yatsen University sponsored by the Ministry of Education of Taiwan. We would also like to thank Ms. B. J. Wang and Mr. L. S. Zhuang for their help in providing water temperature data. We also appreciate the help in the field work we received from Mrs. C. K. Liang, Y. C. Liu, I. F. Chung and Ms. C. H. Tsai. 


\title{
EFFECTS OF NUCLEAR POWER PLANT THERMAL EFFLUENT ON MARINE SESSILE INVERTEBRATE COMMUNITIES IN SOUTHERN TAIWAN
}

\author{
Yalan Chou*, Ta-Yu Lin*, Chen-Tung Arthur Chen**, and Li-Lian Liu*
}

Key words: thermal effluent, marine, sessile invertebrate.

\begin{abstract}
The present study aimed at determining the impact of cooling water discharge from a Nuclear Power Plant in Kenting, Taiwan on the recruitment patterns of marine invertebrates. Field experiments were conducted over a six-year period in the vicinity of the power plant, with six control sites, five at influent areas, one at reference site, and three experimental sites at effluent areas. In general, among the monitoring sites, polychaetes and bryozoans were the most abundant organisms, and their recruitment on settlement plates was always higher in influent than in effluent areas. Partially as a result of a 5-week accidental shutdown of the power plant in the early spring of 2001, a higher recruitment of both polychaetes and bryozoans, comparable to that in influent areas, was observed in the spring and summer of 2001, but only at site Efflu, one of the three effluent areas. Albeit right nearby, site Efflu2 intriguingly showed no such increase in recruitment, MPT as well. Based on the monitoring results, it is strongly suggested that the different patterns of recruitment in the effluent areas can not just be attributed to thermal effects; on the contrary, other physicochemical disturbances seem to have been at play.
\end{abstract}

\section{INTRODUCTION}

The biological consequences of cooling discharge have received considerable attention over the last several decades. In areas of discharge, such physical and chemical disturbances as residual chlorine, elevated temperatures, increased suspended matters, decreased chlorophyll a and dissolved oxygen may pose serious threats to aquatic organisms (Perkins, 1974). Among those factors, raised temperature in effluent environments had received much attention. Depending on the

Paper Submitted 11/02/04, Accepted 03/31/05. Author for Correspondence: Li-Lian Liu.E-mail: lilian@mail.nsysu.edu.tw.

*Institute of Marine Biology, and NCKU-NSYSU Research Center for Ocean Environment and Technology, National Sun Yat-sen University, 70 Lien-hai Road, Kaohsiung, Taiwan 804, R.O.C.

**Institute of Marine Geology and Chemistry, National Sun Yat-sen University, 70 Lien-hai Road, Kaohsiung, Taiwan 804, R.O.C. design and the operating units of the power plants, after passing through condensers, the water temperature in the effluent sites might raise as much as $8^{\circ} \mathrm{C}$ (Laws, 1993). In tropical oceans, this circumstance might lead seawater temperatures over $30^{\circ} \mathrm{C}$ in summer, which may approximate or even exceed the upper limits of the resident organisms (Jokiel and Coles, 1974, Suresh et al., 1993, Wright et al., 2000). In most cases, motile organisms are able to avoid the unfavorable discharges by swimming away. However, sessile organisms are inevitable from the thermal impacts in the effluent areas, and might be killed easily. For instance, Jokiel and Coles (1974) monitored shallow-water corals at Kahe Point, Oahu, Hawaii, and found the corals were bleached or dead near the power plant drainage, and the entire benthos were killed over a large area of Biscayne Bay, Florida when the water temperatures were $4^{\circ} \mathrm{C}$ above the ambient (Zieman and Woods, 1975). Not surprisingly, the addition of warm water from cooling drainage may very well lead to substantial adverse effects on the diversity of fouling communities (Sasikumar et al., 1993, Suresh et al., 1993).

In light of this, the present study was conducted to determine whether the recruitment patterns of sessile invertebrates were indeed affected by the discharges of cooling water from the nuclear power plant located next to the Kenting National Park area in Nanwan Bay in southern Taiwan (Fig. 1).

\section{MATERIALS AND METHODS}

To monitor whether the nuclear power plant drainage was altering populations of sessile organisms on temporal and spatial scales, settlement plates were placed at 9 sites, comprising those in influent areas (i.e. Influ2, Influ-3, Influ-5, Influ-10 and Influ-11) and effluent areas (i.e. Efflu, Efflu2 and Mao-pi-tou (MPT)) as well as at the reference site, Shi-new Shi (SNS), in 5 - 10 meters deep (Fig. 1). The PVC plates $\left(20 \times 20 \mathrm{~cm}^{2}\right)$ were 
fixed horizontally with three replicates on steel frames at each site, and the plates were collected at the end of each season to determine the respective amounts of recruitment of sessile organisms from 1998 to 2004. The four seasons from spring to winter were defined as January-March, April-June, July-September and October-December, respectively.

The number of sessile organisms in different phyla, i.e. mollusks, tunicates, corals, barnacles, polychaetes and bryozoans, were counted seasonally and expressed in terms of occurrence per $\mathrm{cm}^{2}$. The Multi-Dimensional Scaling (MDS) method was employed to analyze and compare the recruitment patterns of sessile organisms among different sites.

\section{RESULTS}

Although four of the six types of sessile organisms, namely mollusks, tunicates, corals and barnacles, were observed on some of the settlement plates, the number of more than one-half of all plates were zero occurrence per $\mathrm{cm}^{2}$ during the experimental period. Thus, the analysis only covers polychaetes and bryozoans which are the two most abundant organisms.

On the question of seasonal variations, in the $1^{\text {st }}$ season, the highest recruitment of polychaetes was observed at Influ-5 in 2004, with an average occurrence of 0.94 per $\mathrm{cm}^{2}$ (Fig. 2), whereas that of bryozoans was at Efflu-2 in 2003, with an average occurrence of 0.99 per

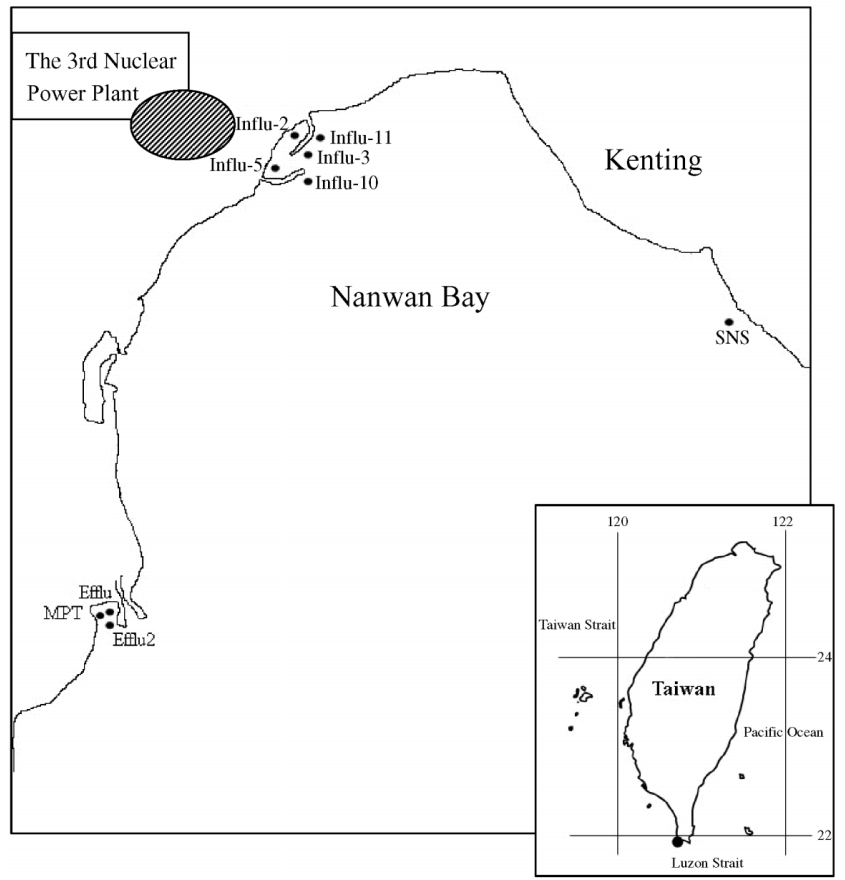

Fig. 1. Detailed map showing the location of the nuclear power plant and the sampling sites. $\mathrm{cm}^{2}$ (Fig. 3). In the $2^{\text {nd }}$ season, the highest recruitment of both polychaetes and bryozoans were at Influ-5, and their respective average occurrence per $\mathrm{cm}^{2}$ was 0.78 in 2004 and 0.97 in 2001. In the $3^{\text {rd }}$ season, the highest recruitment of both organisms occurred at site Influ-2, with an average occurrence of 0.95 per $\mathrm{cm}^{2}$ for polychaetes in 1999 and 0.84 for bryozoans in 2002 . In the $4^{\text {th }}$ season, polychaetes had the highest recruitment with an average occurrence of 1.00 per $\mathrm{cm}^{2}$ at Influ-5 in 1998; the highest recruitment of bryozoans with an average occurrence 0.71 per $\mathrm{cm}^{2}$ was at the same site but in 2003, 5 years later. Additionally, there was no consistent annual pattern in the recruitment of both polychaetes and bryozoans during the experimental period (Fig. 4).

Turning to spatial variations, the relative abundance of both polychaetes and bryozoans differed in the influent and effluent areas (Figs. 2-4). In general, higher recruitment was found in the influent areas than either in the effluent areas or at the reference site. However, with the power plant having accidentally shut down during the March 18 to April 25, 2001 period, particularly noteworthy is that at Efflu in the $2^{\text {nd }}$ and $3^{\text {rd }}$ seasons, 2001, higher recruitment of polychaetes was found in that year, and it was quite comparable to that in the influent areas (Fig. 2). Worth noting too is that this enhanced recruitment at Efflu was not observed at Efflu2 although the two sites are close to each other. These results were further analyzed following the MDS method.

What became apparent is that during the shutdown period (the $2^{\text {nd }}$ season of 2001), Efflu shifted into the influent group, while in general trend, the influent and effluent areas were separated into two distinct groups (Fig. 5). This difference, moreover, lasted into the next season.

To sum up, on the temporal scale, the amount of recruitment of polychaetes and bryozoans was, by and large, quite similar among seasons. By contrast, on the spatial scale, the recruitment of polychaetes and bryozoans was significantly higher in the influent areas than that in the effluent areas in all seasons $(p<0.01$, ANOVA test).

\section{DISCUSSION}

Clear differences in the recruitment of polychaetes and bryozoans were observed in the influent and effluent areas of the power plant. More specifically, for both polychaetes and bryozoans, recruitment in the influent areas was greater than that in the effluent areas (Figs. 2 and 3 ).

The drainage from the power plant has monitored for its ecological impact over a considerable length of time, and as a result, it has been firmly concluded that since drainage draws large amounts of water to cool condensers, large volumes of pelagic organisms and 

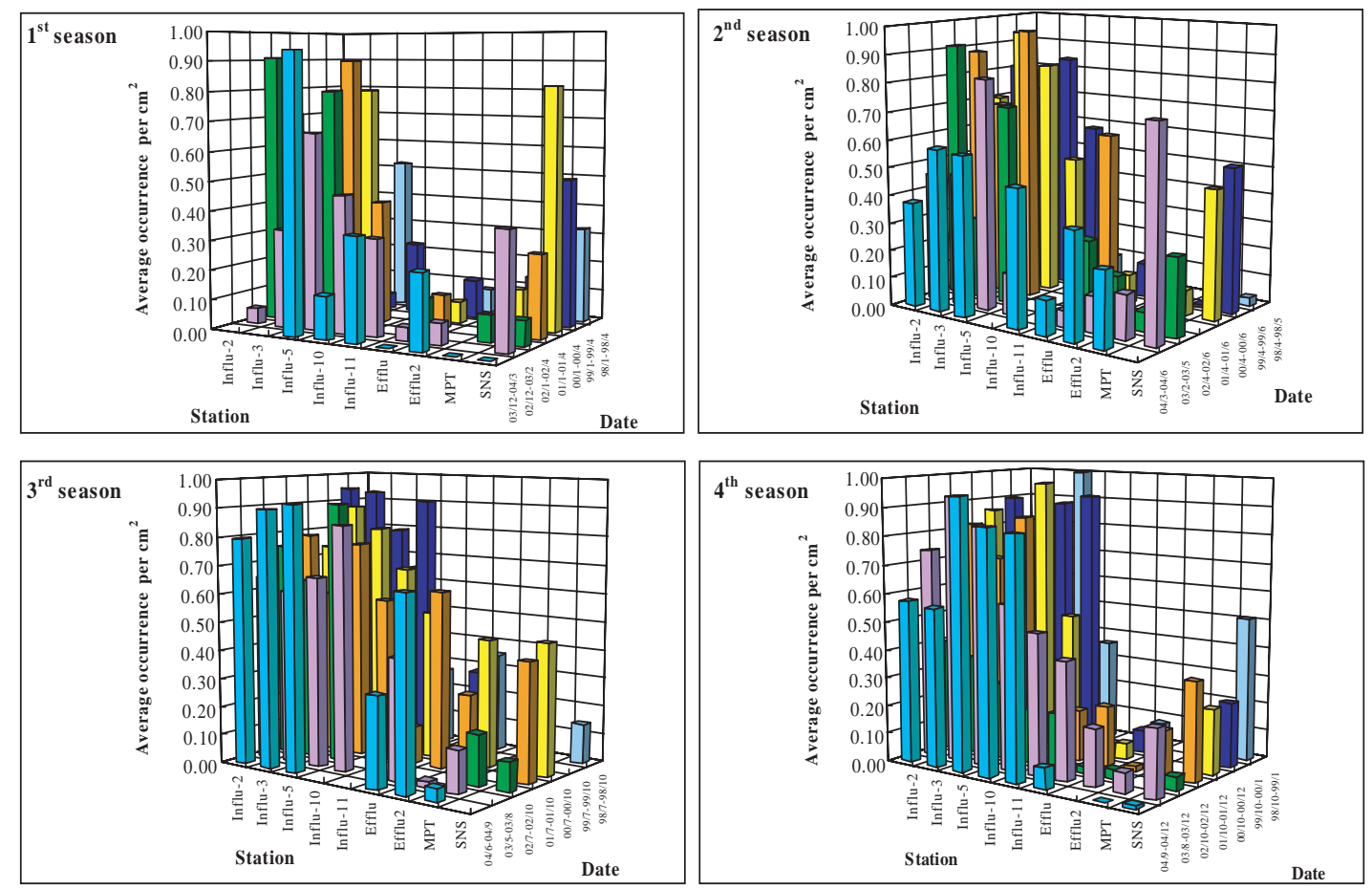

Fig. 2. Recruitment of polychaetes by season from 1998 to 2004, with the colored bars indicating the observation periods.
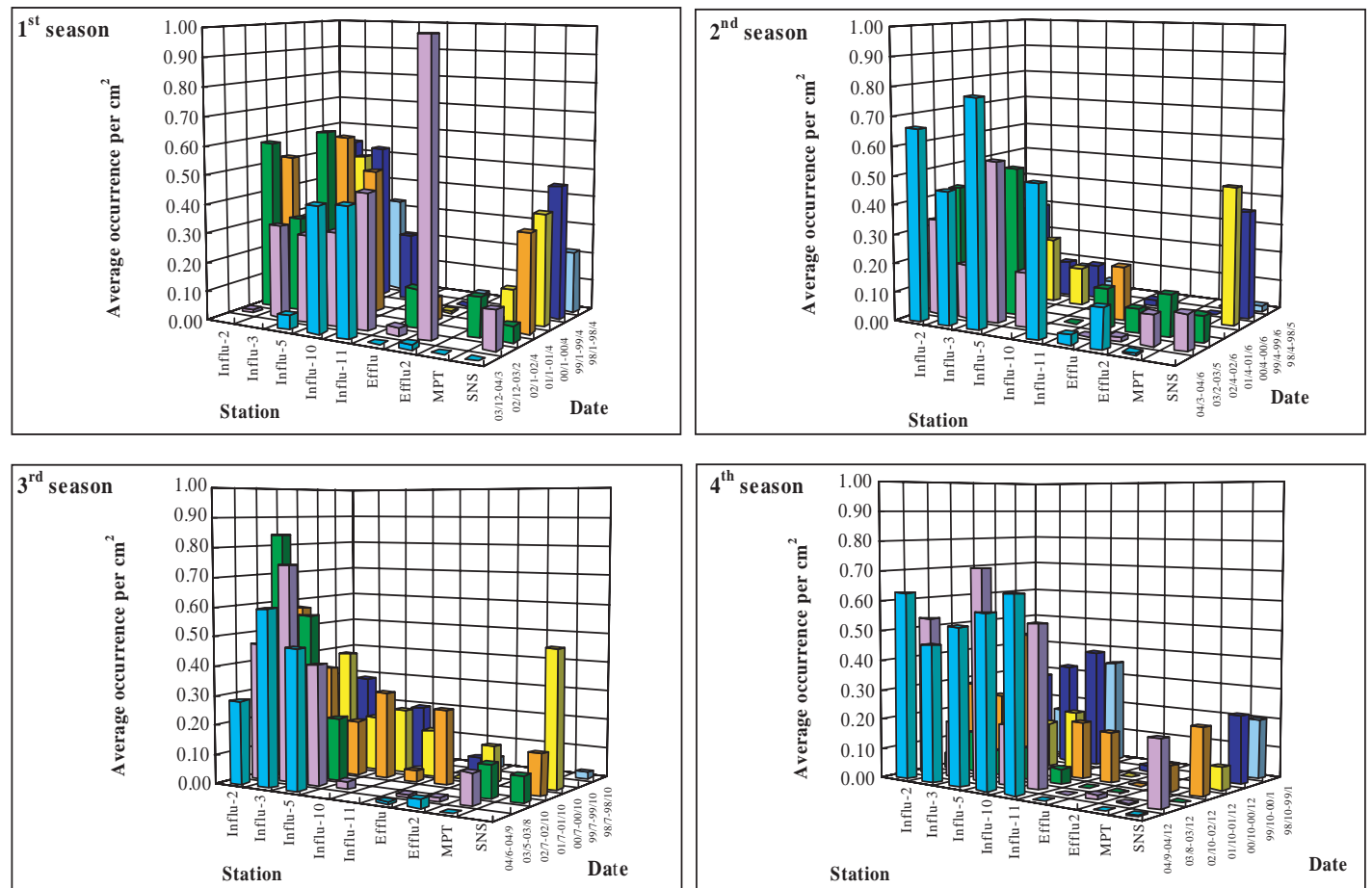

Fig. 3. Recruitment of bryozoans by season from 1998 to 2004, with the colored bars indicating the observation periods.

larvae are also gathered up in the process (Perkins, 1974). Thus, an abnormally high recruitment rate in the intake areas is resulted from such concentrating effect.
In addition, on account of the high velocity of water flow in the drainage areas, as a rule, the local environment is more than likely highly affected. In support of 

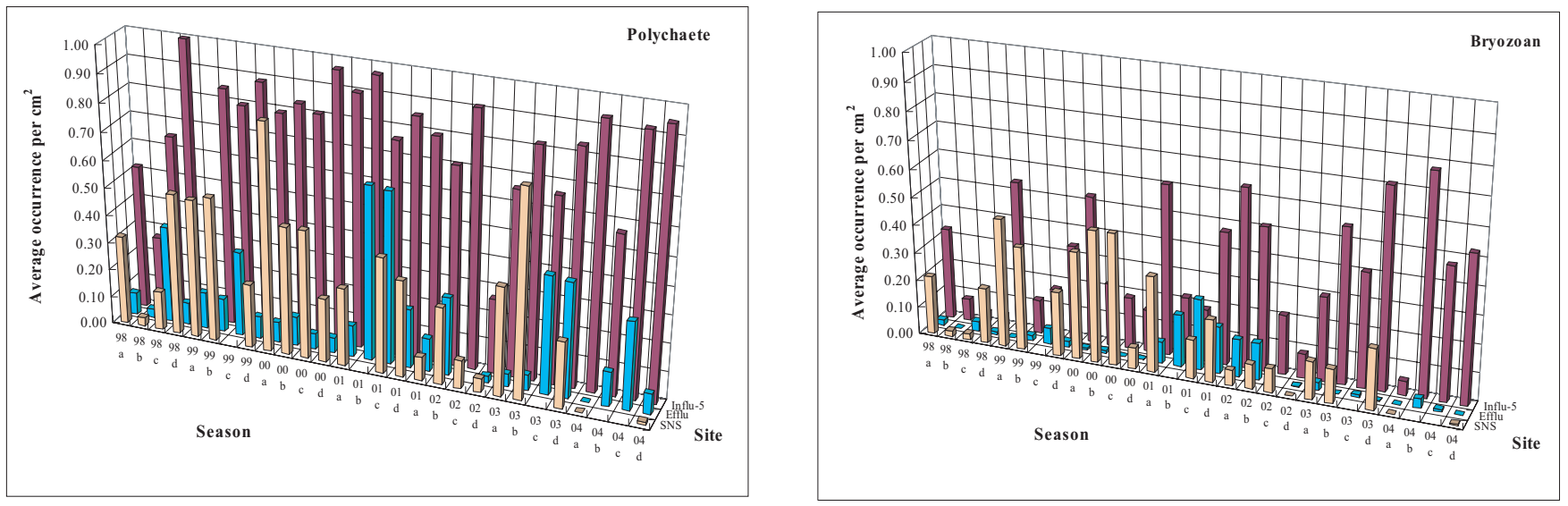

Fig. 4. The recruitment of polychaetes and bryozoans by season from 1998 to 2004, with the colored bars indicating the observation sites of Influ5, Efflu and SNS. a: Spring (January-March); b: Summer (April-June); c: Fall (July-September); and d: Winter (October-December).
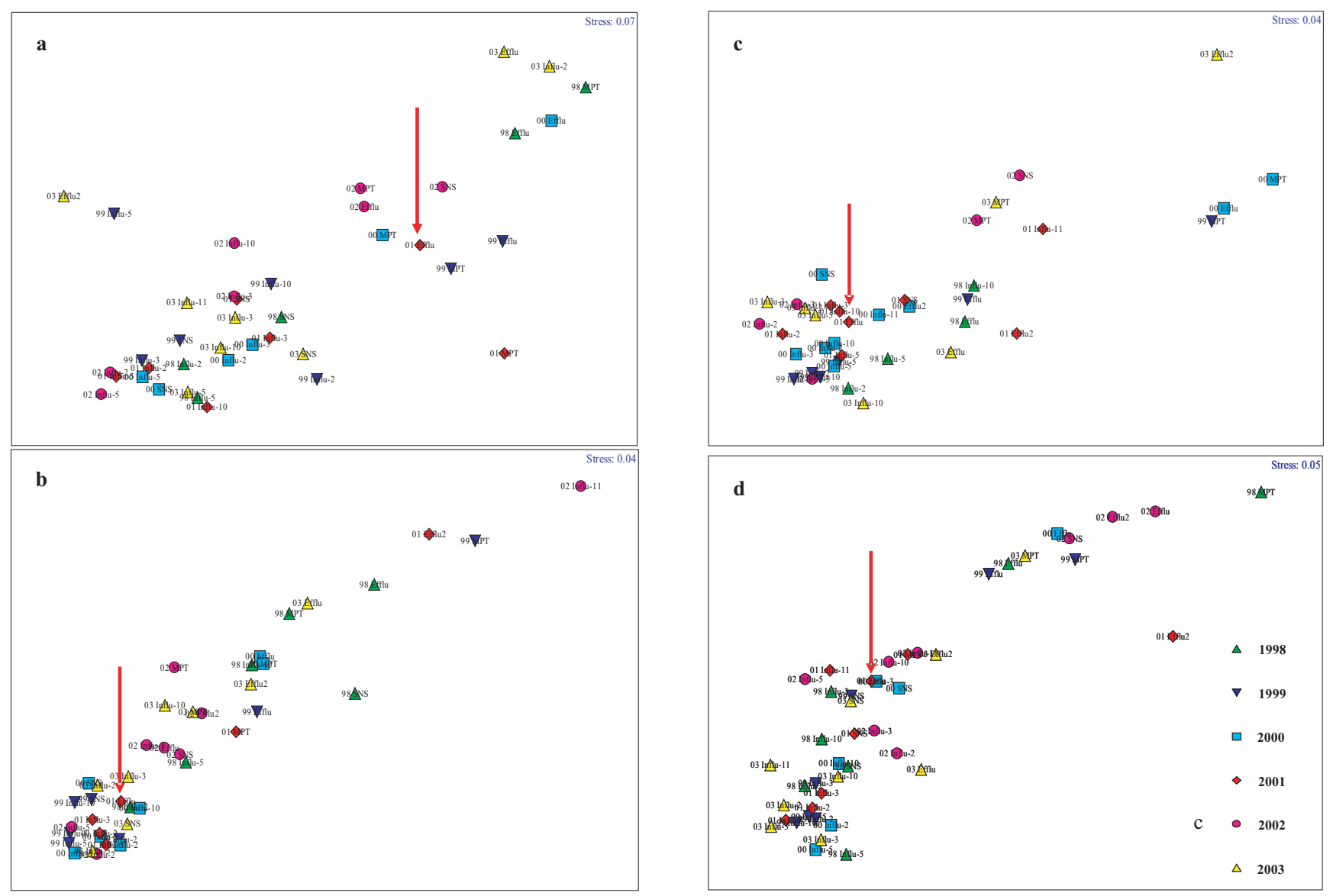

Fig. 5. The MDS analyses of the six types of sessile organisms (i.e. mollusks, tunicates, corals, barnacles, polychaetes and bryozoans) in the influent and effluent areas and at the reference site in the four seasons (1998-2003). a. Spring (January-March); b. Summer (April-June); c. Fall (JulySeptember); and d. Winter (October-December); $\downarrow$ : Efflu (2001).

this, Crisp (1959) contended that water flows supply large quantities of food for sessile organisms and enhance egg production in barnacles. It is also possible that the greater recruitment of polychaetes and bryozoans in the influent areas in the present study is also water flow related as Crisp stated [4]. 
A long term monitoring on the marine communities has been started in 1979 which was coped with the construction and operation of the nuclear power plant. During the period of 1980-1990, at fixed stations, the impact of warm water from the drainage the succession of benthic invertebrates was insignificant (Jan et al., 1994). Based on the experiments of tracing the warm water mass, it was suggested that the monitoring sites were beyond the influenced area (Su et al., 1988, Hung, 1989). However, a serious event of coral bleaching occurred near the water discharge outlet in parallel to 4$5^{\circ} \mathrm{C}$ increase of water temperature in 1987 (Hung et al., 1998). As follows, the global warming event during 1998-99, a wider scale of coral bleaching occurred in the local waters.

It should be kept in mind that the effluent areas in this study were more complex than the influent ones. The impact of the addition of warm water from the drainage of the Nuclear Power Plant aside the effluent areas here were located in the recreational area of Kenting National Park which attracts many tourists for diving activities all year round (Chung et al., 2002). The low recruitment in the effluent areas, therefore, may have resulted from many other disturbances, such as sewage discharge, diving pressure and so on; thus, further study is necessary to evaluate the effects of all the potentially destructive factors.

Since recruitment was higher than normal at Efflu during the shutdown period, the water flow from the drainage might have played a prominent role in altering the recruitment of sessile organisms. If the water flow changed, however, then it follows those local environmental factors, e.g. maximum upper temperatures, the range in temperature fluctuations, residual chlorine and the flow itself may have also contributed, though probably to varying degrees, to the disparities in the recruitment of these sessile organisms. Given that the only site affected by the shutdown event in spring 2001 was Efflu (Fig. 5), factors other than those related to temperature itself must have also been important in resulting in such a phenomenon. Never before, however, have any of these factors been investigated in this study area.

\section{AKNOWLEDGEMENTS}

We are most grateful for financial support from the Taiwan Power Company and the joint project of $\mathrm{Na}-$ tional Cheng-Kung University and National Sun Yatsen University sponsored by the Ministry of Education of Taiwan. We would also like to thank Ms. B. J. Wang and Mr. L. S. Zhuang for their help in providing water temperature data. We also appreciate the help in the field work we received from Mrs. C. K. Liang, Y. C. Liu, I. F. Chung and Ms. C. H. Tsai.

\section{REFERENCES}

1. Chung, K.N., Li, J.J., Meng, P.J., Han, C.C., Kuo, C.Y., Chiou, S.D., Song, G.S., Liang, N.K., Fang, L.S., and Shao, K.T., "Long-term Monitoring of the Marine Ecosystem of Kenting National Park for the Impact of Anthropogenic Factors," J. Nat. Park, Vol. 12, No. 1, pp. 52-73 (2002).

2. Crisp, D.J., "Factors Influencing the Time of Breeding in Balanus balanoides," Oikos, Vol. 10, pp. 275-289 (1959).

3. Hung, T.C., The Preliminary Report for the Assessment of Ecological Impact of the Operation of the Third Nuclear Power Plant on the Nanwan Bay, NSCPE, Academic Sinica, Taipei, Taiwan, (1989).

4. Hung, T.C., Huang, C.C., and Shao, K.T., "Ecological Survey of Coastal Water Adjacent to Nuclear Power Plants in Taiwan," Chem. Ecol., Vol. 15, pp.129-142 (1998).

5. Jan, R.Q., Dai, C.F., and Chang, K.H., "Monitoring of Hard Substrate Communities," Biomonitoring of Coastal Waters and Estuaries, Kramer, K.J.M. (ed.), CRC Press, Boca Raton, FL, pp. 285-310 (1994).

6. Jokiel, P.L. and Coles, S.L., "Effects of Heated Effluent on Hermatypic Corals at Kahe Point, Oahu," Pac. Sci., Vol. 28, pp. 1-18 (1974).

7. Laws, E.A., Aquatic Pollution, John Wiley and Sons, Inc., NY, pp. 313-350 (1993).

8. Perkins, E.J., The Biology of Estuaries and Coastal Waters, Academic Press Inc., London, pp. 576-577 (1974).

9. Sasikumar, N., Azariah, J., and Nair, K.V.K., "Changes in the Composition of a Tropical Marine Fouling Community at a Power Plant Discharge," Biofouling, Vol. 6, pp. 221-234 (1993).

10. Su, J.C., Hung, T.C., Chiang, Y.M., Tan, T.H., Chang, K.H., Shao, K.T., Huang, P.P., Lee, K.T., Huang, C.Y., Fan, K.L., and Yeh, S.Y., An Ecological Survey on the Waters Adjacent to the Nuclear Power Plant in Southern Taiwan. IX. The Progress Report of the Ninth Year Study (1987-1988) and the Preliminary Report for the Assessment of Ecological Impact of the Operation of the Power Plant (July 1979-June 1988). Special Publication No. 59, National Scientific Committee on the Problems of Environment, Academic Sinica, Taipei, Taiwan (in Chinese) (1988).

11. Suresh, K., Ahamed, M.S., Durairaj, G., and Nair, K.V.K., "Impact of Power Plant Heated Effluent on the Abundance of Sedentary Organisms, off Kalpakkam, East Coast of India," Hydrobiologia, Vol. 268, pp. 109114 (1993).

12. Wright, J.F., Winder, J.M.R., Gunn, J.M., Blackburn, J.H., Symes K.L., and Clarke, R.T., "Minor Local Effects of a River Thames Power Station on the Macroinvertebrate Fauna," Regul. Rivers: Res. Manag., Vol. 16, pp. 159-174 (2000).

13. Zieman, J.C. and Woods, E.J.F., "Effects of Thermal Pollution on Tropical-type Estuaries, with Emphasis on Biscayne Bay, Florida," Tropical Marine Pollution, Wood, E.J.F. and Johannes, R.E. (Eds.), Elsevier Scientific Publ. Co., Amsterdam, pp. 75-98 (1975). 